\title{
An Exploratory Study of the Types and Roles of Skincare Advertising Visuals in Magazines
}

\author{
Anurag G. Hingorani, University of Technology Sydney, NSW, AUSTRALIA
}

Abstract: Despite the observations that visuals are almost always present in skincare ads, and that they are noticed to a greater extent than the text in these ads, there appears to be virtually no publicly available research that has analysed the visual content of skincare ads. As visuals might be useful to consumers in assessing the effectiveness of skincare products, their role in influencing consumer behaviour needs to be researched. Before such research is undertaken, it is necessary to investigate visuals that are actually employed by skincare marketers given the large number of products and varied visual cues or stimuli that seem to exist. The purpose of this research is to identify some of the types (or elements) and roles (or functions) of skincare advertising visuals and examine the extent to which they are evident in ads selected from the April through August 2005 issues of four popular women's magazines in Australia. 24 elements and five functions of skincare advertising visuals were identified, and their presence or absence was assessed in a sample of 52 ads. Due to the exploratory and time-specific nature of this study, future research that audits the visual content of magazine advertisements in the skincare market over a longer period could facilitate an extensive investigation of its impact on consumer attitudes and behaviour.

Keywords: Skincare Advertising, Visuals, Magazine Advertisements

\section{Introduction}

A

USTRALIA HAS THE highest rate of skin cancer in the world (Lee 2002, Sartor 2004,

The Cancer Council Australia 2007). This is not surprising given that Australians are exposed to the sun quite significantly owing to their beach and outdoor lifestyle. Consequently, they are a strong market for skincare products that can prevent, reduce, or reverse sun damage to their skin. According to market analysts BU Australia, the Australian skincare market is booming and in 2003 grew $11.4 \%$ to $\$ 771$ million (Devine 2004). Propelled by the strong demand, marketers have exposed consumers to advertisements for a plethora of skincare products, especially in magazines, that tout numerous claims. The variety of skincare products and claims in Australian magazine ads can cause confusion and lead to scepticism by consumers (Hingorani 2002).

Prior research addressing the advertising strategies of skincare marketers (Hingorani 2002, 2005) has focused on the verbal content of ads, such as headlines and body copy (Hingorani 2006). Such content typically imparts information about the advertised product or service. However, visual elements also convey information and are an important component of many advertisements (Pracejus 2003). The importance of visuals also stems from the observation that they are almost always present in skincare ads even when there is no headline or body copy. Despite their importance and prevalence, there appears to be lim- ited publicly and/or freely available research that assesses visuals in skincare ads. Thus, the purpose of this research is first, to examine the types (or elements) and roles (or functions) of skincare advertising visuals and second, to examine the extent to which they are evident in skincare ads. This is achieved by analysing ads from four popular women's magazines in Australia and with reference to prior research on advertising visuals (e.g., Rossiter and Percy 1980, Stewart and Koslow 1989), and in particular, the work of Moriarty (1987).

\section{Selection of Skincare Advertisements}

Skincare products can be broadly grouped into therapeutic and non-therapeutic (or cosmetic) products. However, the boundary between the two groups has become increasingly blurred as cosmetic products for the skin might also be used for their "health" benefits. An example could be a moisturiser which not only improves the skin's appearance (cosmetic) but also provides relief from dry, itchy skin (therapeutic). Relatedly, some skincare specialists such as dermatologists perform cosmetic services such as microdermabrasion, which could be argued is performed not only for cosmetic reasons but also for the psychological health or well-being of the individual.

Given the overlap of health and cosmetic functions of some products in the skincare market, this research examined ads from selected women's magazines for skincare products that are predominantly used to 
improve the skin's appearance (cosmetic) even though some might also have the potential to improve or maintain the health of the skin (therapeutic). Specifically, skincare products for the face (except eyes and lips) and body (e.g., cleansers, moisturisers, toners, and exfoliants) were examined. Products that were not examined include the following: make-up products containing skincare ingredients (e.g., lipstick, foundation, skin whiteners or lighteners or illuminators); personal hygiene or bath care products (e.g., deodorants, soaps, shower gels or milks, body washes, hair removal creams, etc.); products for cellulite and stretch marks; skin disorder care products (e.g., those marketed for their effects on psoriasis, eczema, acne, rosacea, etc.); and sun care products (e.g., those marketed as sunscreens as well as tanning lotions with skincare ingredients). This selection of skincare ads has been previously used in other research that has primarily assessed the verbal content of skincare advertisements (e.g., Hingorani 2002, 2005). It should be noted that ads with single as well as multiple products, and of different formats (e.g., half-page, full-page, double-page spread etc.), were examined.

These skincare ads were chosen from four popular women's magazines in Australia (evident from their typical circulation figures), namely, Cleo, Cosmopolitan, marie claire and The Australian Women's Weekly. Collectively, these magazines reach a crosssection of Australian women, both younger and more mature. marie claire was particularly selected because it appeared to have a lot of ads on skincare products. This has also been found to be the case in its issues in other countries that are culturally quite similar to Australia, namely, the UK and USA (Moeran 2001). The Australian Women's Weekly was especially included because despite its title, it is a monthly publication like the other magazines and has a diverse readership of mature and younger women. Consequently, it could potentially give a more complete picture of the types and roles of skincare advertising visuals than might otherwise be obtained by selecting only niche or highly targeted magazines.

The April through August 2005 issues of the four selected magazines were included in this research. This is because the months of April through August reflect the cooler months or the Autumn-Winter period in Australia during which one might expect to see advertised more of the types of skincare products that were selected for this study such as moisturisers and less of those that were excluded from this study such as tanning lotions with skincare ingredients. The former products might be used to a greater extent in the cooler months and the latter, in the summer months, when one is outdoors.

The year 2005 was chosen to investigate skincare advertising visuals in magazines for a couple of reasons. Firstly, to establish a starting point for a longer-term, longitudinal study with a view to analysing the developments in this area every five years or so. Secondly, in late 2004, skincare marketing giant Procter \& Gamble launched the SK-II skincare brand in the Australian market using an Australian Hollywood celebrity Cate Blanchett and focusing more on print (i.e., magazines) and other media rather than on television (Veldre 2004). From this it was inferred that the year 2005 might have heralded increased activity or renewed interest from other companies, with respect to advertising skincare products in magazines in Australia.

\section{Types or Elements of Skincare Advertising Visuals}

Based on prior research on advertising visuals (e.g., Rossiter and Percy 1980, Stewart and Koslow 1989) as well as a sample of skincare ads drawn from the April through August 2005 issues of four popular women's magazines in Australia, the following types or elements of advertising visuals are expected to be evident in the skincare market:

1. Product(s)/package(s) only shot [This is similar to "straightforward picture of the product" mentioned by Rossiter and Percy (1980)]

2. Product(s) and presenter(s)

3. Presenter(s) using or demonstrating product [This is similar to "product-in-use" mentioned by Rossiter and Percy (1980)]

4. Ingredient(s) only shot

5. Ingredient(s) and $\operatorname{product}(\mathrm{s}) /$ package(s)

6. Ingredient(s) and product(s)/package(s) and presenter(s)

7. Celebrity presenter [This includes those who are not easily recognisable but identified by name in the ad as well as those who are easily recognisable as celebrities - e.g., Andie MacDowell (actress), Natalie Imbruglia (musician), Claudia Schiffer (supermodel), etc.]

8. Non-celebrity presenter(s)

9. Celebrity presenter and non-celebrity presenter(s)

10. Illustration

11. Photograph

12. Illustration and photograph

13. Black and white ad [even if the product's colours are not black and white]

14. Colour ad [even if the product's colours are black and white]

15. Primary Face shot, eyes open/closed [there might be more than one face shot of the presenter, so the focus here is on the dominant (primary) face shot]

16. Primary Face shot, mouth open/closed 
17. Primary Face shot, teeth shown (or "smiling")/teeth not shown (or "not smiling")

18. Primary Face shot, eyes towards/away from magazine reader

19. Body shot, facing/away from magazine reader

20. Setting directly related to normal product use or purchase situation [This type of visual specified by Stewart and Koslow (1989) could include illustrating the application of skincare at home in the bedroom, for example.]

21. Surrealistic visuals [This type of visual specified by Stewart and Koslow (1989) refers to the presence of unreal visuals or fantastic scenes; an example could be a skincare product with wings flying in the air.]

22. Demonstration of product in use or by analogy [This type of visual specified by Stewart and Koslow (1989) could include demonstration of the product in use - for e.g., a woman applying skincare on her face, or a demonstration of the use of the product, benefit or product characteristic by an analogy or device rather than actual demonstration - for e.g., a visual of a dried prune changing to a smooth plum to suggest the anti-wrinkle effect of the skincare product.]

23. Problem and solution (before/after presentation) [This type of visual specified by Stewart and Koslow (1989) could include defining or showing a problem and indicating how the product eliminates or reduces the problem - for e.g., a "before" visual of uneven skin followed by an "after" visual of smooth skin.]

24. Background cast [This type of visual specified by Stewart and Koslow (1989) refers to the presence of people in the ad other than the principal characters; people who serve as scenery or background - for e.g., pedestrians at a traffic light, patrons in a coffee shop, women in a shopping centre, etc. These people are not sources of information about the product.]

It is acknowledged that the aforementioned visual types or elements could be sub-divided into groups or categories, and that this list does not necessarily cover all types or elements of skincare advertising visuals. Additionally, these different visual types or elements are not necessarily mutually exclusive. For example, an ad could contain a photograph (element 11) of a celebrity presenter (element 7).

\section{The Roles or Functions of Skincare Advertising Visuals}

Based on some of the aforementioned types of advertising visuals, it is suggested that skincare advertising visuals perform the following roles or functions:
1. Communicate a product attribute (e.g., smooth consistency of a moisturising lotion)

2. Portray a benefit (e.g., radiant or luminous skin, moisturised skin, etc.)

3. Convey information about product usage (e.g., how to apply a lotion, using a dropper, for example)

4. Communicate an image (e.g., image of quality or luxury)

5. Suggest a feeling or an experience the user could expect by using the product (e.g., joy, excitement, calmness, etc.)

Once again it is acknowledged that the foregoing list is neither necessarily exhaustive nor mutually exclusive. With respect to the latter, an example could be an ad that communicates a product attribute (role 1) and an image (role 4). It should be noted that using the terminology of Moriarty (1987), the above roles could possibly be grouped into the following functions of skincare advertising visuals: literal or symbolic.

According to Moriarty (1987), literal visuals include visuals of identification (e.g., package, brand, logo), description (e.g., what it looks like, parts, attributes), comparison (e.g., between competitors, before \& after) and demonstration (e.g., how to use, apply) whereas symbolic visuals include visuals of association (e.g., lifestyle, typical person, situation), association using a character or celebrity, metaphor (e.g., unexpected substitution based on similarity of some feature - suggesting that the product is like the "substitution" even though they might belong to different domains), storytelling (e.g., drama), and aesthetics (e.g., details become art, pattern, abstraction). Based on Moriarty (1987), it could be suggested that roles 1 and 3 are captured by literal visuals and the other roles by symbolic visuals.

Given that there are different types (or elements), and different literal or symbolic roles (or functions) of skincare advertising visuals, an exploratory study was conducted to determine the extent to which they are evident in selected skincare advertisements.

\section{An Exploratory Analysis of Skincare Advertising Visuals}

In order to determine the extent to which literal and symbolic visuals (that indicate different roles or functions) as well as different visual types are present in skincare advertisements, a sample of advertisements from the April through August 2005 issues of four popular women's magazines in Australia was selected. The magazines were Cleo, Cosmopolitan, marie claire, and The Australian Women's Weekly. After the ads met the selection criteria previously described (see section titled 'Selection of Skincare Advertisements'), they were further screened, and 
removed if they were duplicates or triplicates within and across magazines, and were advertising men's skincare products. Thus, out of an initial 103 ads, 52 were ultimately selected for examination. These included ads containing multiple and single products as well as ads of various sizes such as double-page spread, full-page, etc.

It was found that 18 out of 52 ads $(35 \%)$ contained product or package shots only. This suggests that although 'product only' is a fairly prominent visual type in approximately a third of the skincare advertisements, there are other visual types that appear to be employed. Less prominent among these are the visual types of 'ingredients and product package' ( $2 \%)$ and 'ingredients and product and presenter' $(19 \%)$. More prominent among these is the visual type of 'product and presenter'; 23 out of 52 ads (44\%) contained this type of visual. This suggests that the presenter plays an important role in the communication strategy of skincare advertisements. Perhaps the presenter is employed to raise consumer awareness about the product or to create a positive attitude towards it. Regardless, these findings suggest that many marketers might not view the visual types that focus on products and/or ingredients alone to be as effective in getting a consumer's attention as those that also focus on the presenter. A counterargument could be that those who do not use presenters might in fact be of the viewpoint that presenters do not always stand out in, but add to, the clutter of skincare advertisements in magazines.

It was found that of the 23 presenters in the ads containing the 'product and presenter' visual type, $5(22 \%)$ were celebrities, $17(74 \%)$ were noncelebrities, and one ad (4\%) contained both a celebrity and a non-celebrity. Using non-celebrities more frequently than celebrities in ads that also contained a visual of the product suggests that advertisers are perhaps trying to associate their product with presenters that the target audience can more easily identify with, and believe. However, this is counter to the argument that celebrities, who are usually actors, singers, supermodels, are in fact a credible source of information about the product. This is because they have to appear in public with skin that looks good and is healthy. Regardless, the ads analysed appear to ignore this fact and underscore the non-reliance of these skincare marketers on celebrities to push their product. From a practical perspective, perhaps marketers might not have used celebrity presenters as frequently as non-celebrities because of associated costs and questions regarding the return on their investment in them. Additionally, it was found that of all ads that had presenters in them, including 10 ads of the visual type 'ingredients and product and presenter', only 4 ads contained visuals of the presenter actually using or demonstrat- ing the product. Thus, out of $33(23+10)$ ads with presenters, only $12 \%$ appeared to imply that using the product will make the consumer's skin appear as healthy and/or beautiful as the presenter. This is probably because marketers are aware that by simply placing a presenter in the ad together with visuals of the product/package and/or ingredients, the consumer might make the connection that their skin will look like the presenter. As it is the consumer who makes the inference that in order to have skin like that of the presenter, the latter must have used the product, the marketer might be less subject to scrutiny by regulatory bodies especially if the presenter does not regularly use the advertised product or uses a variety of different products.

Other findings regarding skincare advertising visuals include the lack of use of illustrations, with all 52 ads (100\%) containing photographs. This implies that photographs are essential for persuading skincare consumers who want to see literal or real evidence rather than figurative or representative evidence which is typically captured by illustrations. It also implies that there were no ads containing both illustration and photograph. Also, it was found that the skincare ads were always in colour $(100 \%)$, even when a product's colours were black and white. This could suggest that colour ads might be viewed as providing more literal evidence than black and white ads. This could be investigated empirically and with reference to consumers' credibility perceptions with regard to colour versus black and white advertising visuals in the skincare market.

Apart from the visual types or elements of 'illustration' and 'black and white', there was a complete absence of the following visual types: ingredients only (which could suggest that the finished product with or without the presenter is viewed as being more important by marketers and presumably, consumers), setting directly related to normal product use or purchase situation (which could suggest that advertisers might not believe it is necessary to indicate where one could apply skincare products as this is of little importance to the product's credibility, and adds nothing to the persuasive message that is aimed at consumers), and background cast (which suggests that advertisers do not wish to distract consumers by using presenters that do not represent, or are incidental to the product).

With respect to facial elements of presenters, the findings were as follows: Out of 33 ads with presenters, $28(85 \%)$ presenters (specifically, the main presenter if there were two presenters) had an eye open (sometimes a portion of the face was cut off, hence both eyes were not always evident in the visual), and 5 (15\%) had their eye(s) closed. In ads where the presenter had an eye open, 22 (79\%) ads had eye(s) towards magazine reader with the remain- 
ing $6(21 \%)$ ads containing eye(s) away from magazine reader. This could suggest that skincare advertisers and consumers believe that a presenter is more credible or objective if her eye(s) are open and she looks the reader directly in the eye. This could also be tested in future empirical studies. Out of 20 facial shots in which the presenter's mouth was open, teeth were shown in $16(80 \%)$ of them. Typically when the teeth were visible, the presenter was seen to be laughing or smiling. This could be interpreted to mean that advertisers believe that such visuals engage consumers as they are skimming through magazines or it could mean that the consumer will be happy using the product. Such interpretations could be tested empirically. There were 13 facial shots in which the presenter's mouth was closed and hence teeth were not shown. The greater number of facial shots in which the presenter's mouth was open compared with those in which the presenter's mouth was closed (20 vs. 13), could imply that marketers prefer presenters to be seen as approachable, friendly, and open (mouth open) rather than aloof, tight-lipped, and closed (mouth closed). This is probably because a happy or open presenter could transfer positive attributes to the product. However, sometimes the presenters are models who typically appear aloof on the catwalk of fashion shows. So using presenters in print ads that appear aloof could in fact lend some authenticity to the advertisement and the advertised product. Regardless, this could also be investigated empirically.

Out of 52 ads, only 5 (approx. 10\%) contained body shots, which indicates the emphasis on facial visuals in the skincare ads analysed. Of the 5 body shots, only one shot was facing the magazine reader $(20 \%)$. This could perhaps reflect the need to present scantily clad or unclad body visuals of presenters in a modest light; one way of achieving this would be to have a body shot away from the reader $(80 \%)$.

Another finding from the analysis is that only 2 ads (4\%) contained a surrealistic visual. One could argue that these surrealistic visuals were mild because one was of a ray of light falling onto a drop of product, and the other was of a solid product (i.e., cream) misting up into air. A stronger surrealistic visual might be a jar of cream with wings and flying in the air. The lack of surrealistic visuals could be an indication that skincare advertisers are distancing their products from concepts of fantasy, distortion, unrealism, which could impact on the perceived credibility of skincare products.

Of the 16 ads that contained the visual type of 'demonstration of product in use or by analogy', 6 (37.5\%) ads used presenters (of these, 4 presenters actually held or demonstrated the product or product benefit), and 10 (62.5\%) did not. Thus, more skincare advertisers appear to have resorted to demonstration by analogy. Examples of demonstration of a product by analogy include visuals such as a dry, wrinkled prune changing to a smooth, plump plum (to indicate the moisturising properties of a skincare product), and water exploding from a product like a fountain (to suggest the product's intense hydrating properties and possibly alluding to the "fountain of youth"). Demonstrating a product by analogy rather than in use by presenters appears to be preferred by skincare marketers perhaps because they are less likely to be subject to the scrutiny of advertising regulatory bodies. This is because using presenters, especially celebrities, to demonstrate their product could result in negative consequences if it is found that they do not use the marketer's product at all, frequently, or exclusively.

The visual type of 'problem and solution' or before/after presentation was evident in only $4(8 \%)$ out of the 52 ads analysed. This suggests that advertisers are careful about providing such visual evidence and probably do so only if the visuals and products in the advertisement can actually be substantiated. The sparsity of the before/after presentation in the case of skincare products was also suggested by Wiechers (2002) who, while discussing products like skincare, commented that "you never see the 'before' and 'after' pictures in cosmetic ads" (p.15).

Finally, of the 52 ads examined, 28 (54\%) contained symbolic visuals, 13 (25\%) contained literal visuals, and 11 (21\%) contained some combination of literal and symbolic visuals. Of the 28 ads with only symbolic visuals, 21 portrayed a benefit (role 2), 8 communicated an image (role 4), and 10 suggested a feeling or an experience (role 5). This suggests that portraying a benefit was of more importance to skincare advertisers than communicating an image, or suggesting a feeling or an experience that the consumer might expect by using the product. It also suggests that in some of the ads with only symbolic visuals, multiple roles were portrayed, i.e., $21+8+10$ or 39 roles were evident in the 28 ads. In the 13 ads with only literal visuals, 9 communicated a product attribute (role 1) and 4 conveyed information about product usage (role 3 ). Thus, it could be inferred that conveying information about product usage appeared to be less important than communicating product attributes. In the 11 ads that contained some combination of literal and symbolic visuals, 9 communicated a product attribute (role 1), 9 portrayed a benefit (role 2), 3 conveyed information about product usage (role 3 ), 1 communicated an image (role 4) and 2 suggested a feeling or an experience (role 5). From this it appears that communicating a product attribute and portraying a benefit are equally important in the sample of ads that contained both literal and symbolic visuals. It also suggests that in some of the ads containing both literal and 
symbolic visuals, multiple roles were portrayed, i.e., $9+9+3+1+2$ or 24 roles were evident in the 11 ads.

Overall, role 2 was most frequently reflected in the skincare ads analysed (30 ads, i.e., 21+9), followed by role 1 (18 ads, i.e., 9+9), role 5 (12 ads, i.e., $10+2)$, role 4 ( 9 ads, i.e., $8+1)$, and finally, role 3 ( 7 ads, i.e., $4+3$ ). This suggests that in the group of ads analysed, portraying a benefit was the most evident and by inference, the most important role of visuals in skincare advertisements and conveying information about product usage was the least evident and by inference, the least important.

\section{Limitations and Future Research}

Given the exploratory nature of this research that involved an analysis of advertisements from a small sample of four women's magazines in Australia over a limited time period, it is acknowledged that the findings from this research are not necessarily representative of advertisements across all women's magazines in all countries. However, this limitation is somewhat mitigated by the seeming global presence of many skincare advertisers and their use of standardised advertising strategies across cultures. This is particularly true for some countries that are culturally similar to Australia, such as the United Kingdom and the United States of America, and less so, for countries like China and India. Future research that examined skincare advertising visuals across cultures could help to paint a broader picture of the types and roles of skincare advertising visuals. Addi- tionally, a broader array of skincare products could be researched, including tanning products and makeup products containing skincare ingredients. The types and roles of skincare advertising visuals in non-print media such as television could also be investigated. However, it is expected that there would be considerable overlap with the types and roles of skincare advertising visuals in magazines which have been outlined in this research.

\section{Conclusion}

This research has identified some different types and roles of skincare advertising visuals and the extent to which they are present in ads selected from four popular women's magazines in Australia. It also supports the position that visuals provide information (Pracejus 2003), which is especially reflected in the roles or functions of skincare ad visuals. Overall, it was found that skincare ad visuals, in decreasing order of frequency, portrayed a benefit, communicated a product attribute, suggested a feeling or an experience, communicated an image, and conveyed information about product usage. As the analysis is preliminary in nature, additional empirical research needs to be conducted to shed more light on this topic, which has been largely ignored. Such research would be important because it has been suggested (Wiechers 2002) that consumers tend to attend to visuals to a greater extent than the text or verbal content of ads for products such as those in the skincare market.

\section{References}

Cleo (2005), Selective skincare advertisements, April-August, Australia.

Cosmopolitan (2005), Selective skincare advertisements, April-August, Australia.

Devine, M. (2004), "Hope in a bottle won't make you look like Cate," The Sun-Herald, August, 15, Sydney, Australia. Hingorani, A. (2002), "Skincare Product Advertising in Australia," in Proceedings of the Second International Healthcare Conference: Global Engagement in Creating Financially Viable Healthcare Systems, Ankara, Turkey, 59-62.

(2005), "Scratching the surface of skincare product advertising in Australia," in Proceedings of the 4th International Conference on Research in Advertising (ICORIA), Saarbruecken, Germany, 301-306.

(2006), "Clear or glossy? The appearance of magazine ad information in the skincare market," in Proceedings of the 5th International Conference on Research in Advertising (ICORIA), Bath, UK, on CD-ROM.

Lee, S. (2002), "Looks that could kill," The Sunday Telegraph, September, 50, Sydney, Australia. marie claire (2005), Selective skincare advertisements, April-August, Australia.

Moeran, B. (2001), "On Entering the World of Women's Magazines: A Cross-Cultural Comparison of Elle and Marie Claire," Working Paper no. 2001-45, Danish Institute for Advanced Studies in the Humanities, Copenhagen Business School, Denmark.

Moriarty, S. (1987), “A Content Analysis of Visuals Used in Print Media Advertising," in Journalism Quarterly, 64, 550554.

Pracejus, J. (2003), "Visuals Are Information: How Meaning is Transferred to Consumers through Executional Elements in Advertising," in Advances in Consumer Research, 30, 174-176.

Rossiter, J. and L. Percy (1980), “Attitude Change Through Visual Imagery in Advertising," in Journal of Advertising, 9(2), $10-16$.

Sartor, F. (2004), "Health Report with Miranda Wood," The Sun-Herald, December, 30, Sydney, Australia.

Stewart, D. and S. Koslow (1989), "Executional Factors and Advertising Effectiveness: A Replication," in Journal of Advertising, 18(3), 21-32.

The Australian Women's Weekly (2005), Selective skincare advertisements, April-August, Australia.

The Cancer Council Australia (2007), National Cancer Prevention Policy 2007-09, NSW: The Cancer Council Australia. Veldre, D. (2004), “Cate is P\&G's secret key,” in $B \& T, 26$ August, Australia. 
Wiechers, J. (2002), “Let’s get visual...," in Soap, Perfumery \& Cosmetics, May, 75(5), 15.

\section{About the Author}

Dr. Anurag G. Hingorani

Anurag Hingorani is an educator and researcher in the broad area of marketing communications, and in the specific area of healthcare or pharmaceutical advertising. His research focuses on issues pertaining to the physical and emotional well-being of the consumer, such as body image, and the communication strategies of marketers who sell products that impact consumer health and well-being. Anurag's research has been presented at healthcare and advertising conferences. He has served as a track chair for healthcare marketing conferences and as a reviewer for consumer research conferences and academic marketing journals. Currently, he is a member of the editorial board of an international journal in the area of pharmaceutical and healthcare marketing. 